\title{
Teachers' Use Of Technology In Science Supports Student Knowledge
}

Wail Zain Fakherji

Graduate PhD Student

Department of Curriculum and Instruction

Mississippi State, Mississippi

\section{Abstract}

7 he phenomenon of technology-enhanced impact on teaching science is explored in this proposal with the goal of addressing the need to foster student understanding through the use of technology. The findings of this research; based on analysis of data from surveys undertaken by teachers and students, are a vivid indication that despite the high cost that accompanies implementation of technology in teaching and learning science through acquisition of hardware and training, there is consensual benefit in terms of increased discernment and ease of scientific knowledge delivery derived from the use of technology. As such, this proposal affirms the need for the incorporation of technology in teaching and learning science as a suitable way of enhancing the delivery of scientific information and concepts, as well as, improving understanding among students.

Keywords: Technology, science, students, teachers, schools.

\section{Introduction}

Technological literacy is fundamental across all walks of life. The technology hallmark provides teachers with the ultimate opportunity to transform by using digital resources to provide knowledge to students. Teachers will be able to create direct impacts by applying technology to teaching the science disciplines. Such disciplines are sometimes deemed to be difficult to comprehend, but technology can provide teachers with simple skills that can promote transfer of knowledge to students for the purpose of enhancing their understanding.

Teacher educators are also deemed to have sufficient knowledge about the technological literacy that has the primary objective of enhancing student understanding in the science disciplines. However, there is need for in-depth research on how 
to expand the knowledge and understanding about scientific technology literacy by professors and other researchers in the field. A high quality of professionalism breeds the high quality content essential to students. In depth understanding from the top down, that is to say, from the professors to the secondary school teachers, will help students differentiate the various instructions emanating from teaching. Students will be able to distinguish between technological instructions and literacy instructions at appropriate times. This study advocates for technological literacy to advance comprehension capabilities.

The purpose of this study stemmed from the need to enhance student understanding through the use of technology. The main goal was to find ways of improving student understanding by equipping teachers with the technological resources necessary to attain technological literacy. This would improve the performance in the science disciplines among the students. The objective of this study was to investigate how scientific technological materials help in creating an impact toward the enhancement of student understanding.

\section{Literature Review}

Revolution has been rampant in the recent past, and technology has proven to be the hallmark of change. My interest emanates from the mere fact that revolution is on course, and hence is applied to all areas across the divide. Education is not an exception. Therefore, teachers are deemed to be equipped with knowledge that can be transferred to students. Technology in its widest nature tends to imply advancements occurring in the computer world. This means it will include all the equipment and machinery developed through the utilization of scientific knowledge.

As stakeholders in the education sector, we need to incorporate technology in our science subjects to boost student knowledge. Most students in our schools are products of the digital era; hence, adapting to such a curriculum would be easy, safe, and fast for them. This would also help teachers, who represent a significant component of stakeholders in the 
education sector. Schedules have been tight over the years in the school setting, but including technology would be a primary step toward attaining what ought to be done in a pre-specified period of time. When learners get to middle school, they should possess the ability to comprehend scientific data. This is achievable through the use of technology as students can easily access the materials to be covered by teachers in a timely manner.

However, technology has proven to be expensive, even though its benefits are unquestionable. Most students use platforms to interact with their teachers through E-learning portals, which can build confidence in students. These platforms tend to help students a lot and can produce better results compared to previous performances (Swarat, Ortony \& Revelle, 2012). It is in this regard I find it necessary to be in the quest of conducting research to inquire if my experience cuts across the board. The time is here to expand the ways of boosting and supporting student knowledge through technology. With the vast resources the world has, it becomes fundamental we utilize them to ensure our students obtain the best of what they are taught. Making them custodians of knowledge will enable them to view issues from a broader perspective and to impact society positively.

This study will be of value to stakeholders in the education sector and as a point of reference to other researchers who might be interested in the topic. Furthermore, the government would be able to provide basic resources to help empower the student and to establish a proper knowledge base within the learning institutions. Appropriate ways would be employed to help boost student understanding while using technology and at the same time meet the challenges that hinder the understanding of students when using it. Teachers and schools themselves would also be able to identify the specific areas that are productive for the students while using the technology. This will help them capitalize on the important aspects of technology to help them improve quality and enhance understanding among the students. 
Unnecessary costs would also be scraped off, saving the school's income and providing them an avenue of utilizing the funds for other investments that might be beneficial to the school.

However, education inculcated with technology has grown broader over the years. Previous research posits that the sector has been impactful on student knowledge. According to Luckin, Clark, Garnett, Whitworth, Akass, Cook\& Robertson (2010), technology was meant to offer lessons to students; hence, it has the capability of taking instructions from the lesson as an opportunity to learn (Luckin, Clark, Garnett, Whitworth, Akass, Cook \& Robertson, 2010). My interest in this topic comes from the fact that people have developed misconceptions about technology and how it impacts education. For far too long, a fallacy forced into people's minds has been that technology successfully created a digital conversation in our classroom settings. People tend to forget the principal aim of technology is to ensure student understanding is at its best. This is the only criterion for determining the relevance of technology in learning, especially in the science disciplines. My motivation also stems from the fact that technology is widely available to people and has become familiar to teachers. The expertise within the teaching fraternity is very fundamental in ensuring that students get motivated to incorporate technology in their academic affairs.

The tendency to use technology will help students familiarize themselves with such systems and, as a result, they will have an in-depth understanding of how these systems work. Technology has been of great benefit to the educational sector. It has boosted knowledge among children. For example, involving them in computer games can really help them learn the spellings and pronunciations of words in various disciplines of their studies, including science. This engagement has immensely reduced the time spent by children doing non-constructive things. The interest in computers has grown even more for students at higher levels. Therefore, technology makes the world appear as if it is a global village. 
Therefore, cases of students not conducting their research as a result of having outdated literature content has been pulled out of the learning space. With the inception of the internet, students can easily perform their research and make presentations in due time. The internet gives a broader content and is much easier to use than the catalogs of the past that could be found in most of our learning institutions. The broad scope of the internet creates an opportunity for every student to present a comprehensive paper and have a deep understanding of concepts within the topic of study. Generally speaking, everyone connected to the internet can access the same content simultaneously. This ease allows students to share the information on a larger scale as compared to the books, which could prove to be unorganized and could occupy a lot of space on a student's desk. The portability of learning materials such as books, which have to be carried physically, could also become a significant barrier for some students.

However, with technology, thousands of students just need to carry their devices loaded with the content needed to class, eliminating the previously described difficulties. Furthermore, studies reveal a higher student turn out in most academic institutions as a result of advancement through technology. Students are able to improve their performance in class, which has really encouraged those who had given up because of their dismal performance (Holzer \& Baum, 2017). This is a clear indication that students are beginning to understand what is being taught in class. They tend to grasp more concepts, as technology has made it easier to read from any classroom setting without necessarily focusing on the knowledge that reading is happening because technological gadgets have been brought into play.

The technological generation has also revolutionized the mode of study, and now more students are enrolling in distance learning classes as e-learning takes shape in our society. This trend is seen in a positive light as most students are now capable of studying in the school of their choice from any place they live. 
The long and complicated procedures involved in applying for distance education have been simplified because processes have been made easier. The online systems are now more userfriendly for learners, saving time and money. Time as resource plays a very significant role in our lives. There is always a need to use it in a way to achieve goals. Time management helps both teachers and students in these learning environments because teachers can interact online with their students and answer any eventual questions they might have.

However, technology has some limitations as you will find students who might have already understood a concept getting out of context and starting to ask irrelevant questions. Schools are trying to set up proper control measures to curb this trend. Quality control departments have professionals with the expertise to track such weird behaviors that are prohibited by the rules and regulations set by the learning institutions (West \& Bleiberg, 2013).

A high amount of expenditure can arise from transportation and other direct costs that accompany the preparation and attendance of workshops. However, technology has made it possible for students to interact with the best instructors from all points of the globe. This globalization has facilitated understanding among children since it creates a window for students to communicate with their colleagues on the cloud or through video conferencing. Moreover, teachers can instruct various students around the world by engaging them in video conferences. When receiving concepts from the best minds, students tend to have the perception that the concepts have been well explained and hence easily understood.

Technology has been applied widely in the educational sector, but there are still few reports of its positive impact on student learning. This study seeks to find out how teachers use technology in science to boost the knowledge of the student, to establish the impact of technology on student understanding, to determine what motivates teachers and students to use technology, and to assess the efficiency of technology in learning 
institutions. However, the study might be limited by the fact that there is little feedback on the effectiveness of using technology in classrooms.

One cannot tell if students understand concepts through studying various materials from the library or if the facts were accessed as laid down in the internet. Another key challenge might come up when differentiating between understanding and cramming. If the performances of the students is only measured by way of answering questions in examination centers and classrooms, then we might be deceived into thinking they have understood and yet they have only crammed. Many concepts never last in people's minds, especially if they have crammed. Therefore, cramming could cause a setback that might be encountered during this study. However, a detailed analysis and review will be conducted to ensure the objectives of the study have been taken into consideration.

According to West and Bleiberg (2013), schools are deemed to adopt technologies that can give empowerment to teachers. It is in this regard that the best interest of the student will be addressed, hence achieving the optimum goal of student understanding. The databases for various schools should always be updated so they have the capacity of tracking what operates well with their teachers and which technologies do not correspond with the needs of their teachers (West, D. M., \& Bleiberg, J, 2013).

The technologies that are not useful for the teachers should be identified and set aside since they are already rendered to be not applicable. West and Bleiberg (2013) further posit that various technological aspects should be included in the teacher's work plan for the sake of enabling them to attend to their students. Platforms such as Facebook, Twitter, and Snapchat are some of the channels the students can use during their discussions, and where they tend to disagree or agree, they can use the very platforms to seek clarification from their teachers. Such platforms can create more room for comments and teacher-student interaction because issues of the students 
could be handled on a timely basis, especially in scenarios where teachers have included the technological component in their work plan. This type of interaction will also reduce the physical materials most teachers must carry from one class to another. According to West and Bleiberg (2013), the technologies that work best for teachers, hence increasing student understanding in the sciences, are those allowing the teacher to engage fewer resources during his or her duty. These technologies will reduce confusion for students, who can then always get it right from the get-go (West, D. M., \& Bleiberg, J, 2013).

In the past, the sciences represent some of the disciplines in the education curriculum that have been difficult to assess. Through technology, such assessments have been made much easier since evaluation is done online. According to Harry and Baum (2017), online assessment can help fast track student performance and provide the means to work on any weak areas. Over a period of time, the teacher will be able to analyze whether the corrections initiated from either side have yielded any fruits (Holzer, H. J., \& Baum, S, 2017).

Moreover, the online evaluation system has proven to be cheaper than the paper system, which involves a lot of labor. Moreover, one can easily lose track of any analysis being conducted. Furthermore, online evaluation portfolios are rich in formats, hence can take any preference of the teacher in the quest to track student performance. The various forms the collection can take include videos, interactive features, and music, among others.

To enhance the student knowledge through the use of technology, the teachers have to adopt technology in their policy plans. This is one of the best strategies to motivate a proper work plan. Plans gives teachers opportunities to have scheduling priorities so they don't deviate from their major plans as they would have already been listed as priorities. When priorities remain in the scheme, then the implementation phase is definitely going to be a walk in the park. This ease occurs because the teacher would have already budgeted for the 
technology, hence prioritized it to be carried on. Setting common standards for teaching various disciplines across the divide makes it very easy for the students to understand, due to the emergence of technology. The commonality really boosts the performance of students in the science disciplines across the board as difficult things can be made easier.

\section{Research Methodology}

The sample for this research comprised of a single team of 160 eighth grade students sharing the same instructors or teachers. The sample selected for study was also diverse in terms of performance or academic ability of the students, students from both public and private schools, schools from discordant locations and students of distinct races and ethnicities so as to give a good representation of the population in the local school district.

The testing administered by this research using technology tools incorporated into the classrooms and technology surveys completed by teachers and students during the science class. The eighth grade students selected ranged from eleven to thirteen year olds and all came from families situated in the local town.

Surveys were also administered in this research to collect data from students and teachers. The data comprised of answers given by students and teachers pre and post the implementation of technology in teaching and learning science.

The amassed data was analyzed and compared with the objective of determining whether there was improvement in student understanding or knowledge and motivation when a teacher includes technology tools in teaching science.

The answers provided by students and teachers through the surveys were recorded on an Excel spreadsheet for analysis and comparison before being published.

Technology is incorporated into the social lives of students today. When students are busy on their cellphones, playing video games or listening to their Ipods or MP3 players, they are on 
their computers browsing or chatting. Thus, it can be reasoned that the inclusion of technology tools into classrooms would result in increased engagement in the learning process, as well as, student understanding. This is because technology tools are crucial to motivating students to share their sentiments and answer questions through involvement in the lessons. Based on this understanding, it is imperative that teachers or educators discern how technology can be utilized to improve teaching skills and student understanding, reflected through test scores. According to Guzey and Roehing (2009), teachers who have an opened perception of technology and its impact on science education are more likely to incorporate technology-enhanced teaching and learning tools in their curriculum with purpose of developing teaching skills and fostering student understanding unlike those who are hesitant to stray away from the traditional methods of teaching.

The purpose of this research was to demonstrate to teacher, students and schools the need and possible value of utilizing technology to foster student understanding. This research utilized a qualitative research design since the objective was to gain insight in creating knowledge through scientific literacy. Another reason for this choice was because the data collected was based on the individual interpretation of the respondents and on their reactions to the questions. As such, the method used in this study to gather pertinent data was surveys for teachers and students, as well as, analysis of test scores prior and following the incorporation of technology in teaching science in classrooms.

\section{Subject Selection and Description}

There are various schools in the local school district selected in this study. Given the large number of schools, it was not possible to include all of them in this study. In this regard, the sample for this research comprised of a single team of 160 eighth grade students sharing the same instructors or teachers. The sample selected for study was also diverse in terms of performance or academic ability of the students, students from 
both public and private schools, schools from discordant locations and students of distinct races and ethnicities so as to give a good representation of the population in the local school district.

The testing administered by this research using technology tools incorporated into the classrooms and technology surveys completed by teachers and students during the science class. The eighth grade students selected ranged from eleven to thirteen year olds and all came from families situated in the local town.

The sample used in this research was selected through convenience sampling method since the students all shared the same science teacher. This made the results more accurate. The 160 eight grade students in this study were divided into five different classes with equal number of students. In one class, the science teacher taught using the traditional method of teaching involving a whiteboard, book, pen and paper. However, in the other four classes, the teacher incorporated technology in his teaching so as to facilitate blended learning of science involving computers, projectors, Internet access and online testing and communication or feedback.

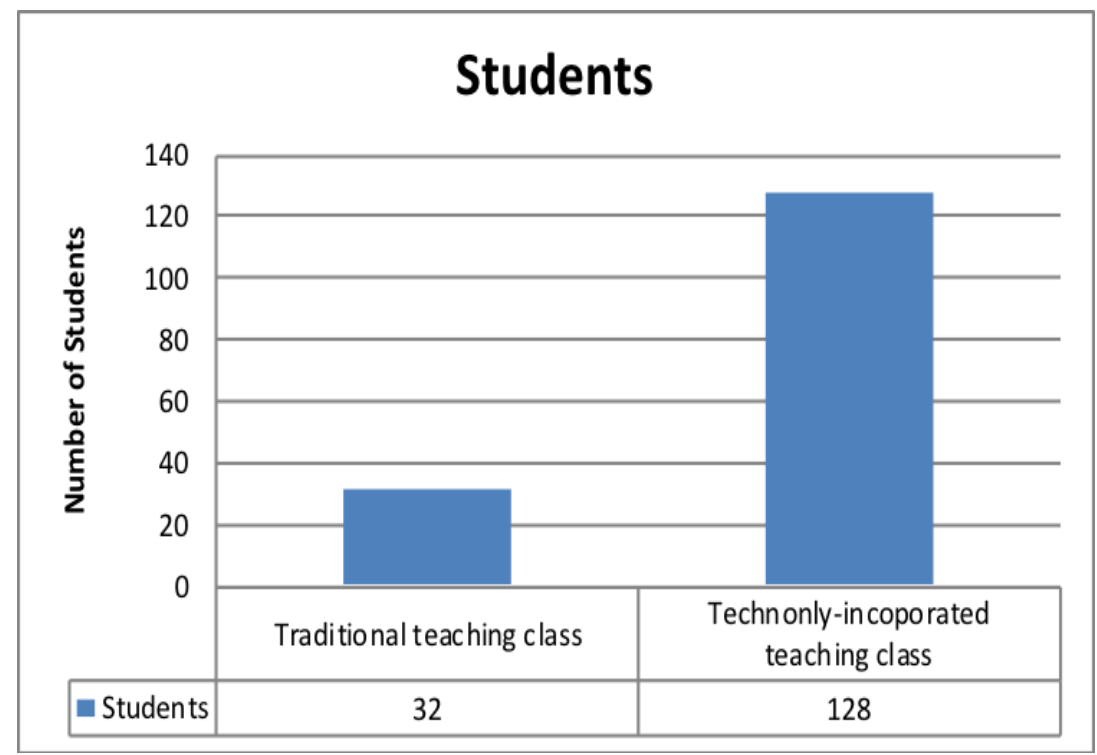


The sampling method was crucial to yielding valid and reliable results given that the same science teacher taught and provided similar instructions to all students in the sample population. All the 150 students in this study were taught by the science teacher in four days with the help of a block schedule that ensure that the students had the same instructions with the only difference coming in delivery. While there are many ways of looking at diversity, the main focus of diversity in the selection of students for this research was in including regular education students, Advancement via Individual Determination students, special education students and gifted students.

\section{Research Instrument}

The main instrument utilized in this research was a survey with various questions formulated specifically for this study. Before the testing period, the students answered user-specific questions and the process was repeated after the testing period. The first section of the survey contained questions that asked students about their attitude toward the effectiveness of the teaching methods in school and toward school in general. For instance, questions such as do you feel motivated to learn the subject, do you think your grade is important, do you like school, what is your mean grade point and what is your favorites subject in school were prevalent in this section. The second section of the survey comprised of questions that asked students about the grades they obtained in the subject of science in the previous semester. The last section had questions that focused on deriving answers from students regarding the technology they were using.

The survey was administered to students in their first science class of a novel semester and teachers during their first faculty meeting. So as to enable every student and teacher to participate fully in the surveys, maximum silence was maintained throughout the process. The survey administered to the students was intended to assess their motivation toward learning, improvement in their understanding and test scores and their attitude toward the use of technology in teaching science. On the 
other hand, the survey administered to the teachers was intended to evaluate their use of technology in teaching science and motivate them to continue incorporating technology into the curriculum.

\section{Data Collection and Data Analysis}

The surveys administered in this research to collect data from students and teachers are outlined in Appendix A and Appendix B. The data comprised of answers given by students and teachers pre and post the implementation of technology in teaching and learning science. The period of data collection was from the beginning of the semester to the end of the same semester. However, the research did not involve all the days of the semester; instead, four convenient dates during the semester were selected to collect the data when it was fresh in the minds of students and teachers which was then analyzed in the same semester.

The amassed data was analyzed and compared with the objective of determining whether there was improvement in student understanding or knowledge and motivation when a teacher includes technology tools in teaching science. The answers provided by students and teachers through the surveys were recorded on an Excel spreadsheet for analysis and comparison before being published. This method of analysis was vital since the surveys were completed by the same teachers and students prior to and following the testing period.

\section{Results}

The results of the survey revealed various impacts of technology in teaching and learning science, as well as, on student knowledge and understanding. For instance, the answers given by the students and teachers evinced that the students were computer savvy and did not experience difficulties while utilizing the technology tools incorporated into their learning regardless of whether they were external tools or software programs. The responses in the survey also showed that students were normally frustrated during the occasions whereby the 
technology did not function properly or when the teachers experienced difficulties using the technology tools to teach. Thus, this was a hindrance when it comes to fostering student knowledge and understanding.

Given the intricacy of incorporation of technology in science education, the surveys showed that teachers emphasized the need for proper training and practice so as to enable teachers to introduce lessons and issue instructions using technology. While most teachers were of the opinion that teaching science using traditional teaching methods was easier than through the use of technology tools, they also noted the increased interest in learning shown by students when they utilized the interactive whiteboards to teach.

When it comes to motivation of teachers to use technology in teaching, approximately half of the responses of the teachers in the surveys revealed that they were willing to continue using technology to teach as long more training and technology workshops were provided by the schools. The other half of the responses by teachers indicated that they were already conversant and comfortable with technology so much so that they were ready to fully implement technology in teaching and learning even without further training.

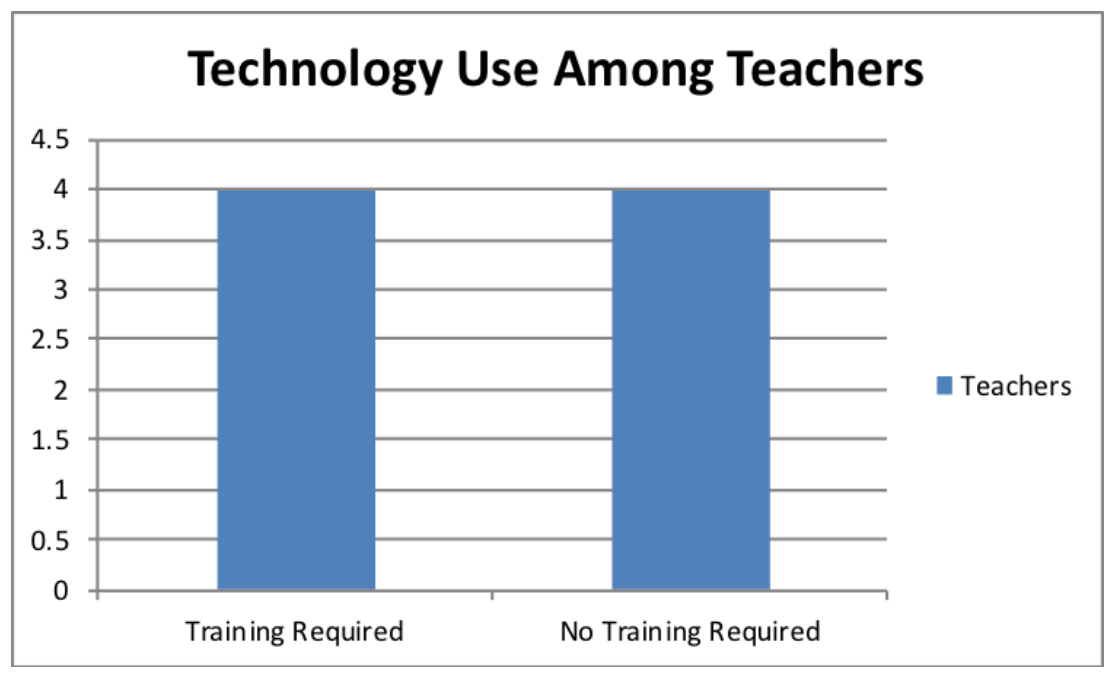




\section{Technonology Use Among teachers}

- Training Required No Training Required

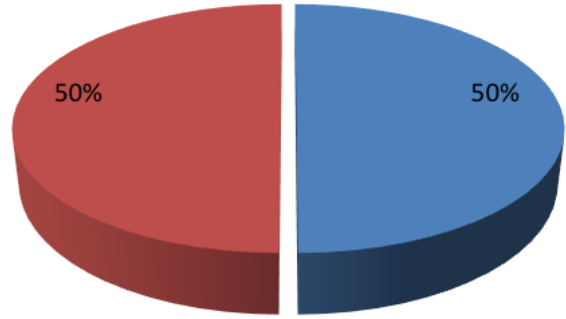

The survey questions administered to students regarding technology tools showed that they were already conversant with the technology tools. For instance, Microsoft software programs are technology tools that the students are familiar with since they have been using them since kindergarten and also at home on computers. In addition, the surveys evinced that the students were pleased with the fact that technology was available in school and as such, they regular got access to some type of technology in school or exposed to them when the teachers used them to illustrate points during lessons in class or during practical lesson in the labs. A significant portion of the students were of the opinion that the inclusion of technology in the classrooms motivated them to gain interest in lessons and improved their understanding of scientific concepts. Notwithstanding, they also revealed that the more time a teacher spent trying to get the technology to work in a certain way, the more they felt distracted in class. In addition, the students did not like it when technology was utilized for repetitive practice and learning and as such, evinced no improvement in knowledge when these methods were used by teachers.

Approximately two thirds of the students who took the survey indicated that their motivation, understanding and grades improved due to the incorporation of technology in teaching and 
learning science and other subjects. The remaining third were of the opinion that the inclusion of technology in teaching and learning made no difference in their understanding and performance, that is, it neither improved nor hindered them.

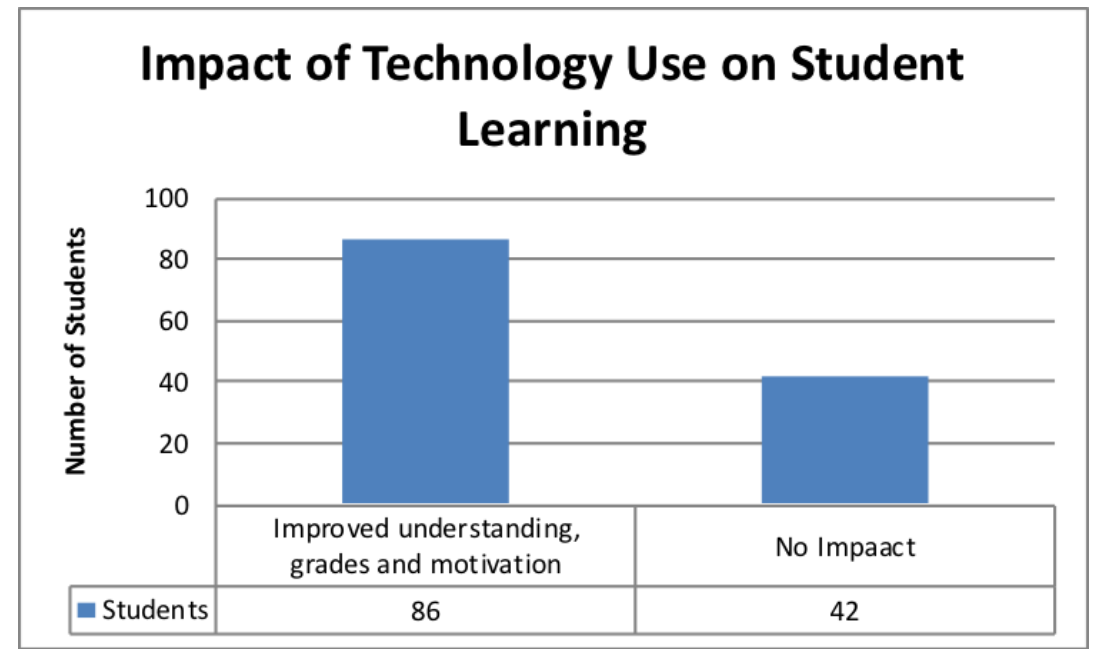

\section{Impact of Technology Use on Student Learning}

Improved understanding, grades and motivation No Impact

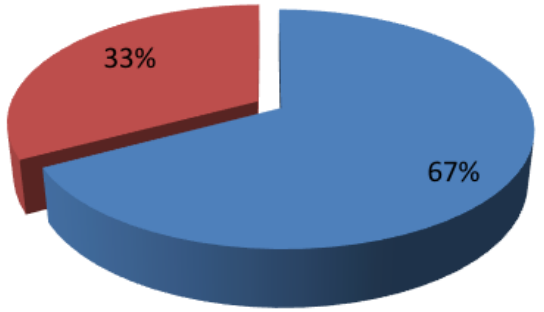

In as much as technology brought about isolation, the surveys evinced that technology also increased participation by students and class attendance. In terms of whether the students 
liked school or not, their perceptions about school did not change with the use of technology. Those who liked school continued to do so and those who disliked school continued to do so regardless of the incorporation of technology in teaching and learning.

Based on the responses of the teachers, the greatest hindrance to technology use in schools was the high cost of acquiring various hardware and software for use in teaching and learning, as well as, training teachers to effectively utilize the technology. Nonetheless, the surveys revealed that with proper budgeting and allocation of sufficient funds by the government, schools could afford to purchase technology tools and train teachers. With regard to the question about what students believed would make them benefit more from the use of technology in schools, the answers revealed that they felt that more "hands on" activities using technology such as Internet use, interactive whiteboard and use of software programs would foster their knowledge and understanding as opposed to teachers lecturing while utilizing technology.

\section{Discussion}

The purpose of this research was to address the need for integration of technology in teaching and learning to foster student knowledge and understanding by administering a survey to teachers and students. The survey revealed that when teachers and schools in general incorporated in technology in teaching and learning science, the student knowledge, attendance, understanding and performance improved. The survey also revealed that students were conversant with most technology tools employed in the school curriculum given that they also use them at home and teachers had a clear perspective of how to use technology to teach and issue instructions in most occasions, but they felt that that could improve with additional training and workshops.

In terms of motivation, teachers who received sufficient training were motivated to use technology to teach and issue instructions in class, but those who lacked proper training and 
adequate time to practice novel technology skills felt less motivated to continue using technology in teaching and often reverted back to their conventional teaching techniques. Technology is vital to improving student knowledge, understanding and performance. However, this impact of technology on student understanding depends on the teachers' knowledge of technology as evinced in the surveys. It is for this reason that training of teachers on technology use is extremely vital to improving student knowledge when technology is utilized in teaching and learning.

\section{Training of Teachers}

This research indicates that the Internet, computers, as well as, interactive and smart whiteboards could be utilized as technology learning tools for all subject areas. Nonetheless, teachers have to take into contemplation the discordant styles of teaching and students ability to learn and understand using with the help of technology tools. This form of teaching requires an alteration in the teacher's technique of teaching, models that compatible with technology and time required to learn how to use the technology as reported by Rimm-Kaufman and Sandilos (2011). Any student who had technology incorporated into the school curriculum regardless of their academic status, that is, regular education students, Advancement via Individual Determination students, special education students or gifted students could see a positive change in classroom motivation, grades and attendance. The survey administered to students in this study affirmed a positive improvement in student understanding and grades when the teachers included technology in teaching and issuing instructions with proper training and suitable planning.

According to West and Bleiberg (2013), training is not only time consuming but also costly, but when teachers are shown how technology can be useful in impacting knowledge in classrooms, most are willing to take time to learn how to use to technology. When technology tools work appropriately in class, teachers who incorporate it directly into the subject of lessons 
and formulate ways of using it as a tool are able to see its effect on the students and overall performance. For instance, discipline problems are fewer in schools, the classroom atmosphere changes and the barricades between students and teachers are supplanted with interactive learning. As indicated in the survey administered to students, interactive learning between teachers and students fostered by technology use was critical to improving student motivation.

When this research was being conducted, the middle school used in this study was in its third years of technology implementation in teaching and learning. As such, the teachers were in the process of learning how to better use technology in administrative use and teaching through activities such as assessing student grades, formulating course worksheets and coming up with course syllabi. From the survey undertaken by teachers, they revealed that teachers not only require adequate time to learn the novel technology but also require ample time to master the technology and feel comfortable using it as a teaching and learning tool. Through the surveys, this study showed that when students and trained teachers began to utilize technology as a tool to complete personal tasks, technology integrated into their personal lives made it easier for them to be more prepared to utilize the same technology in class.

In as much implementation of technology in teaching and learning is hindered by the high costs of acquiring technology tools and training teachers, through proper planning and budgeting by schools and increased investment by the government, technology can be beneficial to students. As reiterated by Polly, Mims, Inan and Shepherd (2010), incorporation of technology at educational institutions requires careful and ample planning that highlights the framework in which technology will be utilized. With time, the use of technology changes the way teachers teach. This means that as they gain more experience using technology, they become more willing to engage in experiments involving technology, establish more collaborative working relationships with other teachers 
and their mode of teaching becomes more student-focused. Based on the results of the surveys conducted by this research, student knowledge, understanding, performance and attendance were fostered when teachers had adequate training and were comfortable using the technology in schools to teach and issue instructions.

\section{Benefits and shortcomings of using technology in teaching and learning}

Based on the results from the surveys, the most prevalent benefit of using technology in teaching and learning the flexibility it renders to students and teachers. With the advancement of technology globally, students can access the Internet anywhere through their smartphones and computers and study at any time or at their convenience. It is for this reason that distance learning has gained immense popularity in schools. Versatility is also enhanced when technology is utilized in schools. Computers can produce different colorful graphics and sounds that are crucial to facilitating the creativity in students. Moreover, computers are capable of providing instant feedback to students when practicing skills learned in classrooms or doing tests supported by technology tools.

As such, students do not have to wait for the teachers to assess their practices and exercise and provide feedback each time; instead, technology tools can assess their progress many times before it is formally evaluated by the teachers in school. The immediate feedback function offered by various technology tools keeps the students interested in their lessons and encourages them to become more active and engaged in learning activities as revealed by students in the surveys. Finally, the Internet is a formidable platform of accumulated knowledge that students can assess easily to acquire information on various subjects from different sources. For instance, if a student is not able to fathom a scientific concept taught in class through the traditional teaching method, he or she can access information from the Internet on that concept and learn from the online 
research. Despite its numerous benefits, using technology in teaching and learning has certain shortcomings or drawbacks.

The ability of technology use to foster student knowledge and understanding is contingent on the teachers' knowledge about the technology. Both the surveys undertaken by teachers and students revealed that the more the teacher was comfortable with using technology, the more the students benefited from technology use. This drawback reiterates the need for adequate training by teachers on information technology which can be costly. Nonetheless, the government has made it a requirement for all teachers to learn how to use technology that they can apply in classrooms and has provided additional funds for training in this front.

Teaching and learning entail immense human interactions, especially when it comes to practical lessons in science. Machines cannot meet all the requirements of human interactions, but an experienced teacher can. Despite the fact that computers can provide instant feedback to students, this feedback is only limited to simple answers, as well as, predetermined comments. Most technology tools are also useful for low-level questions and are incapable of handling questions that require intricate skills from students such as giving pertinent comments, summarizing and taking notes. However, technology was never meant to replace teachers in schools. Its inclusion in schools was only meant to enhance teaching and learning. As such, while through conventional teaching methods there were certain students that the teachers could not reach or motivate to participate in class, technology has provided various avenues to foster interaction between teachers and all students and motivate them to engage in learning actively.

\section{Implications}

From the illustrations identified above based on the analysis of the secondary data, various implications can be drawn. Firstly, the element of teachers feeling betrayed by the government would imply teachers will have lost confidence in the government. It is high time the government rises up with 
speed to ensure it has kept things into order within the education sector. This engagement would restore teacher's confidence in the government and hence technology being used as a tool to instill knowledge in the students. Once the government keeps its house in the education sector in order, it would ensure the main goals involving the student always prevails, which would be an uphill task to be accomplished by any one (Luckin, Clark, Garnett, Whitworth, Akass, Cook \& Robertson, 2010).

Another implication, based on cultural exchange, is that cohesion and integration among countries would be strong in the future. Such an integration is strongly supported because of the technological impact in the education sector. This further implies teacher student interaction from the various spheres of the world would help in boosting the country's economic through foreign exchange when teachers charge students from abroad (Means, 2010). The economic impact within the two countries would result from the trade. Such small beginnings usually grow and eventually create a huge impact when large volumes and numbers of transactions are employed. On the other hand, this beginning would be breeding a society rich in knowledge as the use of technology employed would largely help boost the number of individuals who are elites.

\section{Conclusion}

The objective of this research was to address the need to foster student understanding through the utilization of technology in teaching and learning science by equipping teachers with the technological resources necessary to achieve technological literacy. Through this study, readers will get a clear perspective of how the use of technology in teaching and learning creates a positive impact towards the enhancement of student understanding by promoting flexibility, versatility, as well as, instant testing and feedback despite the constraints that inhibit the potential of technology in fostering student understanding in the context of science education, for instance, high cost of acquiring appropriate hardware and software, as well as, providing sufficient training to instructors to apply 
blended learning instead of just traditional methods of teaching. Notwithstanding, strategies or ways that teachers, students, schools and the government can implement to surmount the constraints of technology use in science education and enhance student understanding include allocation of more funds for training teachers and proper planning by teachers and schools.

\section{References}

Collins, A., \& Halverson, R. (2010). The second educational revolution: Rethinking education in the age of technology. Journal of Computer Assisted Learning, 26(1), 18-27. doi:10.1111/j.1365-2729.2009. 00339.x

Davies, D. (2009) Creatively Teaching Science in the Middle Years Retrieved

from http://www.inclueded.net/writing/science.html

Gazimbe, M.P., Mapolisa, T., Khosa, M.T. and Tshabalala, T. (2015). Scholars Journal of Arts, Humanities, and Social Sciences ISSN 2347-5374 (Online).

Guzey, S. S., \& Roehrig, G. H. (2009). Teaching Science with Technology: Case Studies of Science Teachers' Development of Technology, Pedagogy, and Content Knowledge. Contemporary Issues in Technology and Teacher Education (CITE Journal), 9(1), 25-45.

Holzer, H. J., \& Baum, S. (2017). Making College Work: Pathways to Success for Disadvantaged Students. Washington, D.C. Brookings Institution Press.

Lemke, J. L. (1990). Talking science: language, learning, and values / Jay L. Lemke. Norwood, N.J.: Ablex Pub. Corp., c1990.

Luckin, R., Clark, W., Garnett, F., Whitworth, A., Akass, J., Cook, J \& Robertson, J. (2010). Learner-generated contexts: A framework to support the effective. Web 2.0-based elearning: applying social informatics for tertiary teaching, 70, 70-84.

Means, B. (2010). Technology and education change: Focus on student learning. Journal of Research on Technology in 
Education, 42(3),

$285-$

doi:10.1080/15391523.2010.10782552

Mercer, N., Dawes, L., \& Staarman, J. (2009). Dialogic teaching in the primary science classroom. Language and Education, 23(4),

353-369. doi:10.1080/09500780902954273

Mitchell, M. L., \& Jolley, J. M. (2010). Research design explained: Instructor's edition., 7th ed. Belmont, CA: Wadsworth Cengage Learning.

Polly, D., Mims, C., Inan, F., \& Shepherd, C. (2010). Evidence of impact: Transforming teacher education with preparing tomorrow's teachers to teach with technology (PT3) grants. Teaching and Teacher Education, 26(4), 863-870. doi: 10.1016/j.tate.2009.10.024

Presents, Hobbies. " Teaching Science and Writing in the classroom". YouTube, uploaded by Aaron's Hobbies Presents, $14 \quad$ September 2016, www.youtube.com/watch?v=sn24CvRxPgs

Rimm-Kaufman, S., \& Sandilos, L. (2011). Improving students' relationships with teachers to provide essential supports for learning. Teacher's Modules.

Savelyeva, T. M. Spector, D. Merrill, J. Elen, M. J. Bishop (Eds). (2015):: Handbook of Research on Educational Communications and Technology. Technology, Knowledge \& Learning, 20(1), 123-128. doi:10.1007/s10758-014-9231-7

Simonson, M., Smaldino, S., Albright, M., \& Zvacek, S. (2000). Teaching and Learning at a Distance: Foundations of Distance Education.

Swarat, S., Ortony, A., \& Revelle, W. (2012). Activity matters: Understanding student interest in school science. Journal of Research in Science Teaching, 49(4), 515-537. doi:10.1002/tea.21010

West, D. M., \& Bleiberg, J. (2013). Education technology success stories. Issues in Governance Studies. 